\title{
On carbon footprints and growing energy use
}

\author{
Curtis M. Oldenburg \\ Lawrence Berkeley National Laboratory \\ One Cyclotron Road \\ Berkeley, CA 94720 \\ CMOldenburg@lbl.gov, (510) 486-7419
}




\begin{abstract}
Could fractional reductions in the carbon footprint of a growing organization lead to a corresponding real reduction in atmospheric $\mathrm{CO}_{2}$ emissions in the next ten years? Curtis $\mathrm{M}$. Oldenburg, head of the Geologic Carbon Sequestration Program of LBNL's Earth Sciences Division, considers his own organization's carbon footprint and answers this critical question?
\end{abstract}

In addressing the problem of energy-related greenhouse gas (GHG) emissions and climate change, it is essential that we understand which activities are producing GHGs and the scale of emission for each activity, so that reduction efforts can be efficiently targeted. The GHG emissions to the atmosphere of an individual or group are referred to as the 'carbon footprint'. This terminology is entirely appropriate, because $85 \%$ of the global marketed energy supply comes from carbon-rich fossil fuel sources ${ }^{1}$ whose combustion produces $\mathrm{CO}_{2}$, the main GHG causing global climate change. ${ }^{2}$ Furthermore, the direct relation between $\mathrm{CO}_{2}$ emissions and fossil fuels as they are used today makes energy consumption a useful proxy for carbon footprint. It would seem to be a simple matter to reduce energy consumption across the board, both individually and collectively, to help reduce our carbon footprints and therefore solve the energyclimate crisis. But just how much can we reduce carbon footprints when broader forces, such as growth in energy use, cause the total footprint to simultaneously expand?

In this feature, I present a calculation of the carbon footprint of the Earth Sciences Division (ESD), the division in which I work at Lawrence Berkeley National Laboratory (LBNL), and discuss the potential for reducing this carbon footprint. It will be apparent that in terms of potential future carbon footprint reductions under projections of expected growth, ESD may be thought of as a microcosm of the situation of the world as a whole, in which alternatives to the business-as-usual use of fossil fuels are needed if absolute GHG emission reductions are to be achieved. 


\section{Calculating the carbon footprint}

The first step to efficiently reducing energy-related $\mathrm{CO}_{2}$ emissions is to quantify how much an individual or organization emits through various activities. With the able assistance of a high school summer intern (Jeffrey Y. Chan), and using the many excellent online educational materials ${ }^{3}$ along with guidance from a widely available protocol, ${ }^{4}$ we quantified ESD's $\mathrm{CO}_{2}$ emissions. As a research group, ESD's main contribution to GHG emissions is from energy use. This assumption allows us to focus only on $\mathrm{CO}_{2}$ rather than other GHGs - including $\mathrm{CH}_{4}, \mathrm{~N}_{2} \mathrm{O}$, perfluorocarbons, hydrofluorocarbons, $\mathrm{SF}_{6}$, and $\mathrm{NF}_{3}$, which might be important for an organization involved in agriculture or manufacturing but which we may safely ignore. Using the standard definitions, the various sources of $\mathrm{CO}_{2}$ emissions for a research group such as ESD can be classified into three groups as follows:

1. Scope 1 comprises the direct combustion emissions (or fugitive emissions) at the local facility for example, from heating the buildings (with natural gas) in which ESD staff work.

2. Scope 2 comprises indirect emissions such as from the combustion of fossil fuels offsite (e.g. by a utility or power company) for the generation of electricity consumed by ESD.

3. Scope 3 comprises emissions from energy use that occurs off-site but that is essential to the scientific mission of ESD, such as official travel to meetings and conferences, and employee commuting.

After consideration of the balance of ESD activities, we assumed that the major $\mathrm{CO}_{2}$-emitting activities arising from ESD operations are those related to (i) building energy use, such as lighting, running computers, ventilation, and air-conditioning and heating using electricity and natural gas; (ii) official employee travel mostly on airplanes, but also local travel mostly by automobile; and (iii) commuting. These assumptions led to our excluding GHG emissions from our off-site field activities, from shipping and mailing, and use of water, paper, and other expendable office supplies and equipment. 
With help from various LBNL staff members who provided data on ESD's building occupancy (to estimate natural gas and electricity use from single-meter buildings that we share with other divisions), we calculated ESD's electricity and natural gas usage for a full year. It is notable that the electricity delivered to LBNL is a special low-carbon mix of which $60 \%$ is from non-fossilfuel sources - 40\% hydro, 12\% nuclear, and 8\% renewable (mostly geothermal from the Geysers Geothermal Field in California) - with the remainder 35\% natural gas and 5\% coal.

Administrative staff also provided us with information on official travel destinations and mode of transport. The latitude and longitude of the travel destinations were used to calculate the trip distance using an equation for shortest distance between two points on the surface of a sphere. Finally, a similar process was used to compute commuting distances from residential location data (zip codes), while mode of commute was assumed to be $65 \%$ private car, $30 \%$ public transit, and 5\% bicycle or walking. Next, standard multipliers for mass of $\mathrm{CO}_{2}$ produced per KWh for electricity use, per Therm (or equivalent BTU) for natural gas use, and per passenger mile for air travel, private automobile, and the other various commute modes were used to calculate the total ESD $\mathrm{CO}_{2}$ emissions for one year.

\section{Results}

ESD's annual $\mathrm{CO}_{2}$ emissions were calculated to be 500 tonnes $\mathrm{CO}_{2}$ from natural gas and electricity use, 520 tonnes $\mathrm{CO}_{2}$ from commuting (2 million person miles per year), and 560 tonnes of $\mathrm{CO}_{2}$ from official travel (3 million person miles per year) for a total of approximately 1600 tonnes $\mathrm{CO}_{2}$ per year. I note that this estimate neglects some additional emissions which arise from LBNL-wide shared energy uses, for example, those for major research facilities such as the Advanced Light Source, the shuttle buses, heating and lighting for common spaces such as the cafeteria and conference rooms, elevators, and so on. Assuming a round number of 200 people in the division, the average per capita carbon footprint for an ESD staff member carrying out his or her professional duties is 8 tonnes of $\mathrm{CO}_{2}$ per year. For comparison, a typical US resident's total per capita carbon footprint is 20 tonnes of $\mathrm{CO}_{2}$ per year. ${ }^{5}$ 
To put ESD's carbon footprint in perspective, consider that 1600 tonnes of $\mathrm{CO}_{2}$ is approximately the amount of $\mathrm{CO}_{2}$ in 80 refrigerated $\mathrm{CO}_{2}$ tanker trucks often seen on highways around industrial areas delivering $\mathrm{CO}_{2}$ from refineries to other industrial and food-beverage facilities. Or put another way, 1600 tonnes is the amount of $\mathrm{CO}_{2}$ emitted in about 100 minutes by a $1000 \mathrm{MW}$ coal-fired power plant (8 million tonnes/yr * yr/365 $\mathrm{d} * \mathrm{~d} / 24 \mathrm{hr} * \mathrm{hr} / 60 \mathrm{~min}=15$ tonnes/min).

\section{Reducing the carbon footprint}

So how can ESD go about lowering its energy use and thereby reducing its carbon footprint? First and foremost there's the low-hanging fruit of improved building energy efficiency, which can likely reduce natural gas and electricity use by $20-30 \%$ through improved windows, better

heating and air conditioning systems, motion-sensitive and lower-energy lighting, energy-saving computer sleep modes, etc. Second, commuting appears to be an area in which significant emissions reductions can be made, either by greater use of public transit, biking, or walking, by increased use of car-pooling, or by use of more fuel-efficient cars. With incentive provided by higher gasoline prices, parking fees, or subsidy for car-pooling or mass transit use, I believe the commuting carbon footprint could be reduced by $30 \%$. Finally, there is official travel. With improved video conferencing facilities partially paid for by reduced travel costs, some scientific and professional travel could be eliminated with minimal impact. At first glance it may appear that increased use of video and web conferencing could reduce official business travel considerably; however, my experience is that this is not so easy. Much of ESD's official travel is to conferences and scientific meetings rather than small-group meetings that we already handle by telephone, web, or video conferencing. And there is no sign that scientific meetings will soon decrease either in number or in frequency. Furthermore, for meetings involving several groups of people, some of which travel to the meeting venue, it can be difficult to include other groups via video conferencing, i.e. to hold a meeting in which some people attend in person and others attend 'virtually'. The reason for this is the common use of special rooms for state-of-the-art video conferencing, which invariably seem to have occupancy limitations. Nevertheless, my ballpark estimate is that official travel could be reduced by $20 \%$. In short, it appears that overall 
ESD at its current size could reduce its carbon footprint by approximately 25\% fairly easily by using financial subsidies, incentives, or policy imperatives.

Could these potential reductions in carbon footprint achieved by ESD and by every organization around the world lead to a corresponding reduction in atmospheric $\mathrm{CO}_{2}$ emissions in the next ten years? Unfortunately, the answer is no. Growth in energy use will, in all likelihood, offset improvements in energy efficiency and per capita reductions in GHG emissions. For example, ESD is expected to grow by as much as $50 \%$ in the next few years, which could mean the addition of nearly 100 new staff members. ESD is a small-scale example of the global situation in which human population is predicted to grow from just under 7 billion this year (2011) to 8 billion in 2025 and 9 billion by 2050. ${ }^{6}$ Meanwhile, economic growth and improvements in the standard of living in the developing countries will also occur, thereby further increasing energy use and GHG emissions. So while improvements in energy efficiency and the lowering of per capita carbon footprints in developed countries are essential in helping to address the global energy-climate crisis, they are not enough to avoid significant climate change as long as overall energy use grows and fossil fuels remain the main energy source used as they are today.

It appears the best that fractional reductions in energy use can do in the developed countries, where the standard of living is already high and population growth is leveling off, is to maintain approximately the status quo in terms of carbon footprint. Therefore, additional strategies are needed to meaningfully reduce carbon footprints in the developed countries. Moreover, anthropogenic climate change and the growing populations and improvements in standard of living in developing countries are an additional motivation for the urgent search for solutions to change current energy production practices. Meanwhile, one path that must be pursued is research, technology development, evaluation, and testing of Carbon Dioxide Capture and Storage (CCS) which offers a potential bridge to a new energy future by means of reducing net $\mathrm{CO}_{2}$ emissions from the current carbon-rich energy sources that presently dominate global energy supply. 


\section{Acknowledgment}

This work was supported by the Assistant Secretary for Fossil Energy, Office of Sequestration, Hydrogen, and Clean Coal Fuels, through the National Energy Technology Laboratory, U.S. Department of Energy, under Contract No. DE-AC02-05CH11231.

\section{References}

1. EIA (Energy Information Agency), International Energy Outlook, 2010, U.S. Department of Energy. http://www.eia.doe.gov/oiaf/ieo/world.html Figure 16. [January 7, 2011]

2. IPCC Third Assessment Report - Climate Change 2001, Working Group I: The Scientific Basis, Chap. [January 7, 2011]. http://www.grida.no/publications/other/ipcc_tar/?src=/climate/ipcc_tar/wg1/index.htm

3. Silverman J and Fowler K, The ABC's of GHGs. [Online]. Pacific Northwest Laboratory. Available at: http://www.hss.energy.gov/nuclearsafety/env/training/the_abcs_of_ghgs.pdf [January 7, 2011].

4. The Greenhouse Gas Protocol Initiative. [Online]. Available at: http://www.ghgprotocol.org/calculation-tools/service-sector [January 7, 2011]

5. International Energy Agency (IEA), $\mathrm{CO}_{2}$ Emissions from Fuel Combustion, 2010. http://www.iea.org/co2highlights/co2highlights.pdf [January 7, 2011]

6. U.S. Census Bureau, International Data Base, December 2010 update, http://www.census.gov/ipc/www/idb/worldpopgraph.php [January 7, 2011] 


\section{DISCLAIMER}

This document was prepared as an account of work sponsored by the United States Government. While this document is believed to contain correct information, neither the United States Government nor any agency thereof, nor the Regents of the University of California, nor any of their employees, makes any warranty, express or implied, or assumes any legal responsibility for the accuracy, completeness, or usefulness of any information, apparatus, product, or process disclosed, or represents that its use would not infringe privately owned rights. Reference herein to any specific commercial product, process, or service by its trade name, trademark, manufacturer, or otherwise, does not necessarily constitute or imply its endorsement, recommendation, or favoring by the United States Government or any agency thereof, or the Regents of the University of California. The views and opinions of authors expressed herein do not necessarily state or reflect those of the United States Government or any agency thereof or the Regents of the University of California. 